\title{
A system dynamics approach for estimating the water footprint of the bioethanol supply chain in the region of Orizaba in the State of Veracruz, Mexico
}

\author{
A. Trujillo-Mata ${ }^{1}$, G. Cortés-Robles ${ }^{1}$, C. Sánchez-Ramírez ${ }^{1}$, \\ G. Alor-Hernández ${ }^{1} \&$ J. L. García-Alcaraz ${ }^{2}$ \\ ${ }^{1}$ Graduate and Research Division, \\ Instituto Tecnológico de Orizaba, Mexico \\ ${ }^{2}$ Engineering and Technology Institute, \\ Universidad Autónoma de Ciudad Juárez, Mexico
}

\begin{abstract}
The global pressure to reduce emissions combined with the negative tendency in the world oil reserves is impelling the improvement and development of renewable sources of energy. The bioethanol industry is one of the most active sectors. Under this environment, the market is facing a conflict: to increase productivity (more resources consumed), without compromising the future natural resources. In emergent countries as Mexico, there is not yet a well-developed biofuels supply chain. However, it is growing at a regular pace. As the bioethanol industry accelerates its productivity and market share, another renewable resource suffers for this expansion: the water reserves. This work proposes to integrate the Bioethanol Supply Chain Analysis with the Water Footprint Assessment. Nevertheless, water changes in time under the influence of several factors, producing a complex and dynamic behavior. Therefore, a system dynamics model to evaluate the water footprint of the bioethanol supply chain enables the capacity to simulate the impact of bioethanol production on water resources over time in the city of Orizaba in the State of Veracruz, Mexico.

Keywords: water footprint assessment, system dynamics modeling, bioethanol supply chain, causal loops diagram, emergent biofuel markets, Mexico.
\end{abstract}




\section{Introduction}

In recent years, industries have shown a growing interest in managing water consumption effectively. Water availability for domestic, agricultural and industrial use has become an increasingly important topic of international and interdisciplinary research (Susnik et al. [1]). It is also necessary to consider that water shortage has become an important limiting factor for sustainable development in many countries (Donoso et al. [2]). Moreover, there is also a growing awareness of diverse environmental issues such as global warming and climate change that encourage research to explore the best practices for efficient water consumption. In addition, other factors besides climate change affect the water demand, particularly the increasing rates of population growth and the associated industrial development (Dawadi and Ahmad [3]). Under such restrictive conditions, the underlying logic explains that, as the population of the world increases and water availability decreases, companies must redesign their supply chains (Carter and Jennings [4]).

This paper consists of three sections. The first section offers an overview of the importance that sustainability has in supply chains, specifically biofuels supply chains, as well as why it is recommended to do it from a dynamic point of view. The second section explains the fact that water footprint is a good indicator to evaluate sustainability of supply chains and system dynamics can be an efficient approach to get an insight of water footprint behavior through time. It also explains the advantages of the synergy between the Water Footprint Assessment methodology and the System Dynamics approach. The third section shows the general model of biofuels supply chains in Mexico and presents a preliminary model that incorporates the water footprint concept into the supply chain of bioethanol. This initial model is as an approximation to the hypothesis that water footprint can be modeled and simulated using system dynamics

\section{The need of sustainability in bioethanol supply chains and its dynamical analysis}

The literature reviewed shows that there are still big opportunities to define the best practices and methodologies to help managers to design policies and strategies to improve the supply chain management. The objective of this effort is to ensure the sustainability of supply chains by reducing the environmental impact that they have. According to Winter and Knemeyer [5], the field of Supply-Chain Management has an inherent connection with sustainability. In other hand, according to other works, [6-11], the biofuels supply chain is one of the more dynamic fields looking for better practices for sustainability. It is also crucial to notice that water is not a fundamental element analyzed in the biofuels supply chain. However, local sources supply the water used in biofuel production, and this consumption has social, environmental, economic and industrial impacts (Domínguez-Faus et al. [12] and Hoekstra et al. [13]). In consequence, water plays a vital role in supply chains, especially in biofuels supply chains due to the nature of their raw materials. Therefore, it is necessary for any supply chain, particularly 
in the biofuels supply chain, to determine the amount of water consumed in the production of biofuels, and it is important to know the impact that this consumption will have in the hydrological resources of a specific region. The Water Footprint Assessment is a useful approach to reach this objective. However, like any other systems, the bioethanol supply chain is in constant evolution. Thus, it is necessary to analyze dynamically how the system changes and adapts to an increasing complex market. The System Dynamics Simulation is useful to model and test different scenarios and hypothesis over time; then it has the potential to produce valuable information and to facilitate the decision-making process. Consequently, this article proposes to estimate the Water Footprint of bioethanol in the central region of the State of Veracruz, using the System Dynamics approach. The integration of water footprint assessment with systems dynamics is a useful synergy for several purposes such as:

1) To observe the impact that bioethanol production has over water resources in a specific region,

2) To identify conflicts among different water demanding activities,

3) To identify and prevent conflicts among different actors such as enterprises, agriculture, population, or livestock,

4) To design and implement strategies, policies or normativity for the efficient management of water resources, and

5) To analyze the benefits that new technologies and good practices have on water resources.

\subsection{The biofuels supply chain}

In general, the biofuel industry is growing explosively due to environmental regulations, and renewable or sustainable energy needs. Thus, it is imperative to analyze the biofuels supply chain. An et al. [14] propose a generalized structure based on the agricultural biomass feedstock to examine what currently is known about biofuels supply chains. Other research papers show that it is possible to implement a sustainable and environmentally friendly energy system that creates economic value for a country. This argument is present in the work of Eksioglu et al. [6], who developed a model that searches the minimization of the total cost of a biomass supply chain, accounting for deterioration, seasonality and availability of biomass materials. Nevertheless, sustainability is not a central topic in this article. Zhang et al. [15], explore the sustainability of a biofuel supply chain through a mixed and integer linear programming (MILP) model, nonetheless, the study does not consider the dynamic behavior of the supply chain. A dynamic analysis is useful because biofuel supply chains are complex and have a dynamic performance over time (Barisa et al. [16]). Finally, the water footprint was not included in the evaluation of sustainability.

In [8] the authors developed a model that addresses sustainability issues, however, issues related to water behavior, their impact, its performance over time on the lands, and the most efficient use for these crops is not considered. Månsson et al. [17] use the supply chain approach for analyzing the existing biofuel supply chains in Sweden. None of these works focus on the analysis of the water 
consumption in the case of the bioethanol production. From a different perspective, the work of Avinash et al. [18] describe the biodiesel supply chain. Authors examine the development of biofuel as a substitute for fossil fuels to explore several possible benefits. However, just a few articles analyze the changes that water availability may have because of its consumption within the biofuels supply chain. Despite this lack of information, water availability for domestic, agricultural and industrial use has become an important topic of international and interdisciplinary research that studies the major water challenges that the world is facing in many places [1]. The next section focuses on the analysis of the water footprint in a supply chain and reveals several opportunities.

\section{Integrating the water footprint assessment in the supply chain analysis using system dynamics}

In general, the renewable forms of energy are considered "green" because they cause little depletion of the Earth's resources (Hall and Scrase [19]). Thus, the transformation of biofuels as a sustainable solution for fossil fuels must avoid the intensification of any negative environmental impacts (Love and Nejadhashemi [20]). Then, it is necessary to assess the impact that water consumption has in the region where biofuel is produced. According to Ruini et al. [21], in the last decade, there has been a bigger interest in the evaluation of the water footprint in parallel with the carbon footprint. Authors also mention that although there is a wider interest in the research and assessment of the water footprint of a process, this concept has not a full acceptation as much as the carbon footprint assessment. However, several researchers have carried out studies to evaluate the water footprint in supply chains: Aviso et al. [22] developed a fuzzy input-output model for optimizing supply chains taking into account diverse constraints for water footprint. The Water Footprint Assessment opens the door to the analysis of complex water relationships. This analysis also produces vital information for policy actors, business leaders, regulators and managers about their responsibilities on this increasingly scarce resource (Chapagain and Orr [23]). According to Donoso et al. [2], a useful tool to address the demand-supply imbalance of global water resources is the water footprint (WF). WF is an indicator of freshwater use, which looks not only at the direct water use of a consumer or producer but also at the indirect water use [13]. Thus, the business water footprint considers both, an operational (direct) and a supply chain (indirect) water footprint [21].

\subsection{Why it is important to assess the WF in biofuels production}

There are research studies that assess the green, blue and gray water of bioethanol such as those by Gerbens-Leenes and Hoekstra [24], or the work of Chooyok [25] who calculated the water footprint of ethanol from molasses in two provinces of Thailand based on the methodology described by Hoekstra et al. [13]. Su et al. [26] investigated the water footprint of four energy crops and one food crop to 
determine the water footprint data, according to a region of Taiwan. None of the studies addresses the water footprint from a dynamic point of view.

According to Gerbens-Leenes et al. [27], in the coming decades, human beings will face critical challenges, not only to meet the basic needs for water, but also to ensure that human activities do not affect freshwater ecosystems performing ecological functions. This will put additional pressure on freshwater resources; therefore, it is urgent to propose a process of sustainable intensification by increasing the efficiency of water use. In [12], the authors analyze the management of land and water explaining that as biofuel production increases, a growing need exists to understand and mitigate potential impacts to water resources. The water footprint of biofuel energy depends on the crop being cultivated, the yield selected for this purpose, climatic conditions at the location for production, and agricultural practices [27]. Hence, it is necessary to consider that a continuous growth in biofuel production could have far-reaching environmental repercussions. Globally, water resources are scarce, with industry, a fast-growing urban population, and agriculture competing for it (Deurer et al. [28]). Galan-delCastillo and Velazquez [29] establish that, despite the increase in biofuel production and the amount of research about this issue, the potential effects of associated water consumption have not been analyzed in a rigorous way. Thus, only a few studies have examined the relationship between biofuel consumption and pressure on water resources.

Despite their advantages, the limitations of WFA are the prediction of longterm impacts, as well as the changes that water could have in its availability through time. Consequently, it is necessary to support this methodology with an approach able to deal with the behavior of a system in the time. The System Dynamics Methodology is useful to model and simulate the water footprint of biofuels supply chain through a given period.

Systems thinking is the process of understanding how things, like parts of a set, influence each other. According to Aslani et al. [30], System Dynamics (SD) is a systems thinking based methodology useful to understand and model the behavior and activities of complex systems over time. System Dynamics Models (SDM) utilize Causal Loop Diagrams (CLD), which help analyze feedback loops, variables, levels, and delays that can affect the behavior of a system over a period (Rendon-Sagardi et al. [31]). System Dynamics Models (SDM) are frequently developed to identify complex interactions of variables in different sectors, as well as the definition of policies in water management systems, analysis of energy systems, and in biofuel supply chains [30]. A system dynamics model can depict the interaction and relation that have the different variables of a biofuel supply chain, such as water use and water availability. It is also relevant to underline that the system dynamics approach enables the possibility to model the water behavior as a continuous variable. For a more detailed description about System Dynamics and System Dynamics Modeling, the work of Forrester [32], Rehan, et al. [33] and Chen and Wei [34] is highly recommended.

The integration of the water footprint assessment with a system dynamics modeling process, promises to be significant and worthy, since according to Hoekstra et al. [13], water availability fluctuates in time and consequently, the 
complex relationship of relevant water variables could be represented through a dynamic model.

\subsection{System dynamics modeling for the water footprint in the biofuels supply chain}

The application of system dynamics methodology for different aspects of the biofuel supply chain has evolved in the last decade [16]. Despite this effort, there are just a few works in the area of biofuels supply chain using the System Dynamics approach. In [31], the authors carried one of these studies, developing a System Dynamics Model to evaluate whether the production of ethanol in Mexico could meet the potential demand for this substance as a biofuel additive. Even if this work is relevant, water is not analyzed as an important element of the supply chain of ethanol. The work of Susnik et al. [1] develops a system dynamics model to analyze the current and future behavior of a catchment to assess water scarcity in the Kairouan region, Tunisia. The work of Jin et al. [35] incorporates the system dynamics approach into the ecological footprint for forecasting the ecological footprint. In Rehan et al. [36], the authors developed causal loop diagrams and a system dynamics model to support the financially sustainable management of urban water distribution networks. A different approach to waterrelated issues is the one shown by [34]. Authors explore the applications of system dynamics modeling in water security systems. Finally, they discussed the progress of research on flood control and disaster mitigation using this methodology. In [34], the authors also show that the System Dynamics method presents more relatively mature research and applications in water resource security. The work of El-Gafy [37] was to develop a system dynamics model to explore how the water footprint of crop production and consumption change under certain scenarios.

The literature review validates that no research addresses the integration of water footprint assessment (WFA) using system dynamics for the analysis of biofuels supply chain. The synergy between the Water Footprint Assessment (WFA) and System Dynamics Modeling (SDM), consents several benefits. Table 1 synthesizes the main advantages of this synergy.

Table 1: $\quad$ Main advantages of WFA-SDM synergy.

\begin{tabular}{|l|c|c|c|}
\hline \multicolumn{1}{|c|}{ Advantages } & $\begin{array}{c}\text { System } \\
\text { Dynamics } \\
\text { Modeling } \\
\text { (SDM) }\end{array}$ & $\begin{array}{c}\text { Water } \\
\text { Footprint } \\
\text { Assessment } \\
\text { (WFA) }\end{array}$ & $\begin{array}{c}\text { Integration } \\
\text { SDM- } \\
\text { WFA }\end{array}$ \\
\hline Dynamic simulation of water consumption & Yes & No & Yes \\
\hline Evaluates water resources management & No & Yes & Yes \\
\hline Determines the volume and type of water use & No & Yes & Yes \\
\hline Forecasts the consumption of water by type & Yes & No & Yes \\
\hline Forecasts water availability for a region & Yes & No & Yes \\
\hline Identify future conflicts and their effect & Yes & No & Yes \\
\hline
\end{tabular}

It is important to mention, that despite the fact that system dynamics modeling has the potential for developing comprehensive water system models, there are 
practically no works about the dynamic water footprint assessment of biofuels supply chain. Next section describes the model that results from the integration of the WFA to the SC analysis from the system dynamics perspective, for the region of Orizaba in the State of Veracruz, Mexico.

\section{Proposed model for the WFA in bioethanol supply chain}

Figure 1 shows the current structure for the analysis of a sorghum-and-molassesbased bioethanol supply chain in Mexico. In Figure 2, it is also highlighted the importance that water has as one of the most relevant variables in the bioethanol supply chain. The water performance and its impact on the hydrological bodies of a particular region should be considered to perform an efficient analysis and quantification of the water consumption along the bioethanol supply chain.

The general scheme shown in Figure 1, can be converted into a Causal Loops Diagram (CLD), which is the previous step to the Forrester's diagram modeling that will help simulate the interaction of all the variables that have been identified in the supply chain. An approximation model to the main Causal Loop Diagram that best could help in further research is shown in Figure 2. The Forrester's diagram that is useful to simulate dynamically the water footprint along the bioethanol supply chain is not included in this research work.

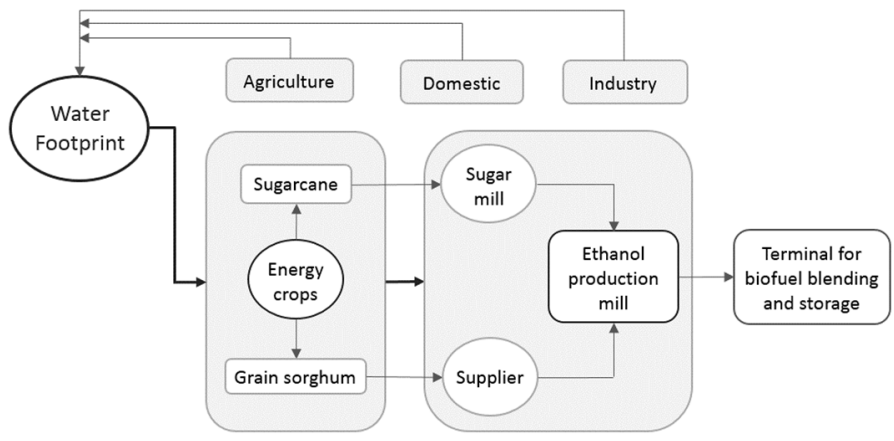

Figure 1: Current structure of a bioethanol supply chain in Mexico with the water footprint variable.

The causal loops diagram in Figure 2 is in the conceptual stage; hence, specific results as well as policy options or strategies are beyond the scope of this paper. They will be related to the conclusions drawn from the research project completion.

Figure 2 is an approximation model that was developed considering the conceptualization for bioethanol production in Mexico depicted in Figure 1. De description of the feedback loops defining the dynamics of the system under study is as follows. In loop B1, if the available area for sugarcane sowing increases, the amount of sugarcane that can also be planted increases. In the other way, if 


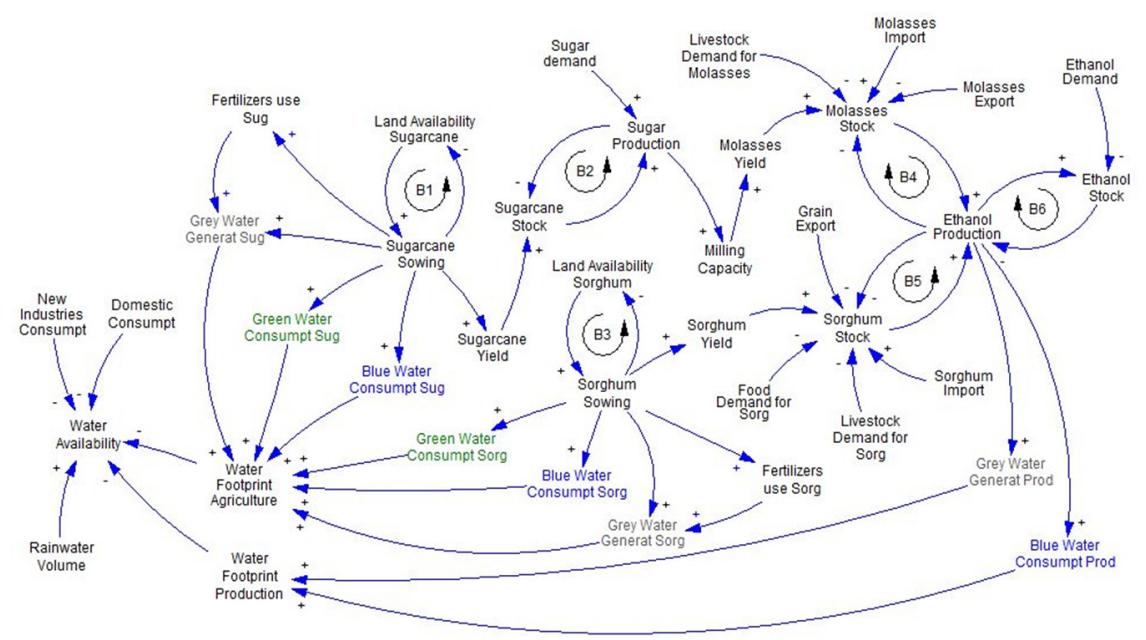

Figure 2: CLD for the analysis of the bioethanol supply chain and its water footprint.

the amount of sugarcane that can be planted increases, the available land decreases. Loop B2 represents the consumption of sugarcane as the result of sugar production. This relation explains that when sugar production increases, the stock of sugarcane decreases. Moreover, if the sugarcane stock increases, the potential production of sugar increases. In loop B3, if the available area for planting sorghum increases, the amount of sorghum that can be planted also increases. In the other way, if the amount of sorghum that can be planted increases, the available land for sorghum decreases. In loops B4 and B5, if sorghum and sugarcane-based molasses stocks increase, the production rate of ethanol increases. In the other hand, if production of ethanol increases, feedstock decreases (molasses and sorghum). In loop B6: An increasing ethanol demand reduces the ethanol stock, which at its turn, increases the ethanol production. In the other sense, a decreasing demand reduces the stock consumption, which affects the ethanol production.

For loops B1 and B3, it is important to consider the availability of land, which according to Babel et al. [38] generates significant social and economic changes because the increasing demand for ethanol reduces the land availability for alimentary purposes. The relation between the variables sugarcane sowing (in the CLD as Sugarcane Sowing) and sugarcane green water consumption (in the CLD as Green Water Consumpt Sug) is positive because if sugarcane sowing increases, the amount of green water consumed, also increases.

The relations between the variables in the CLD shown as Gray Water Generat Sug, Green Water Consumpt Sug, Blue Water Consumpt Sug, and the variable Water Footprint Agriculture, are positive because as the consumption of these types of water increases, the Water Footprint will also increase. The same type of relation occurs for the variables associated to sorghum, and it has an impact also associated to the water footprint of the agriculture stage (in the CLD as Water Footprint Agriculture). 
In regards to the production stage, the variable generation of gray water (in the CLD as Gray Water Generat Prod), and the variable blue water consumption (in the CLD as Blue Water Consumpt Prod), have a positive influence on the variable water footprint of the production stage, represented in the CLD as Water Footprint Production. This effect explains that if any of these consumptions becomes greater, then there is a greater impact of the water footprint for the region under study.

Figure 2 also reveals several conflicts: (1) an increasing demand for food will produce a higher pressure on the system, reducing the land availability and thus the potential production of ethanol. (2) The domestic water consumption and the available water for agriculture purpose will suffer some stress if the ethanol industry demands more water. (3) A higher demand for ethanol will reduce land availability and water availability. Thus, any government policies to promote ethanol consumption must take into account both kind of resources. (4) As an emergent country, Mexico is strengthening its industrial activity that undoubtedly will consume more resources. Thus, the economic and industrial conditions are favorable to accept some guidelines and recommendations for selecting the right kind of industry in a particular region.

\section{Conclusions}

The present study proposes an analysis for the estimation of water availability and its behavior from a dynamic perspective. This emergent research topic takes relevance when the analysis considers water as one of the most important elements in the biofuels supply chain. Consequently, this article also proposes a model, which is able to incorporate the water footprint assessment of biofuels, specifically bioethanol, in its supply chain analysis, for the region of Orizaba in the State of Veracruz, Mexico.

The model has a particularity: it is possible to evaluate the performance using the System Dynamics approach since its modeling technique could help the bioethanol industry to develop policies and strategies that contribute to fulfilling the sustainability requirements of its supply chain. The CLD is an original attempt to show how the water footprint concept can be modeled with the system dynamics methodology.

As a future work and improvement of the proposed model, it is necessary to consider the analysis and assessment of the water footprint in all the stages of the supply chain, including the distribution stage of biofuel. More knowledge and insight about the ethanol industry will be available if the oil production system and market fluctuations are taken into account in the present analysis. However, the complexity and effort to model this integration will also increase.

\section{Acknowledgements}

This work was supported by the National Council of Science and Technology (CONACYT) under grant number 333272; the Public Education Secretary (SEP) through PROMEP; the Tecnológico Nacional de México (TNM); and the ROPRIN (Network of Optimization in Industrial Processes) under grant number 260320. 


\section{References}

[1] Susnik, J., Vamvakeridou-Lyroudia, L.S., Savic, Dragan A. \& Kapelan, Z., Integrated system dynamics modeling for water scarcity assessment: Case study of the Kairouan region. Science of the Total Environment, 440, pp. 290-306, 2012.

[2] Donoso, G., Blanco, E., Franco, G. \& Lira, J., Water footprints and irrigated agricultural sustainability: the case of Chile. International Journal of Water Resources Development, 2015. DOI: 10.1080/07900627.2015.1070710

[3] Dawadi, S. \& Ahmad, S., Evaluating the impact of demand-side management on water resources under changing climatic conditions and increasing population. Journal of Environmental Management, 114, pp. 261-275, 2013.

[4] Carter, C.R. \& Jennings, M.M., Logistics social responsibility: an integrative framework. Journal of Business Logistics, 23 (1), pp. 145-180, 2002.

[5] Winter, M. \& Knemeyer, A.M., Exploring the integration of sustainability and supply chain management: Current state and opportunities for future inquiry. International Journal of Physical Distribution and Logistics Management, 43 (1), pp. 18-38, 2013.

[6] Eksioglu, S.D., Acharya, A., Leightley, L.E. \& Arora, S., Analyzing the design and management of biomass-to-biorefinery supply chain. Computers and Industrial Engineering, 57, pp. 1342-1352, 2009.

[7] Ewing, M. \& Msangi, S., Biofuels production in developing countries: assessing tradeoffs in welfare and food security. Environmental Science and Policy, 12, pp. 520-528, 2009.

[8] Akgul, O., Shah, N. \& Papageorgiou, L. G., Economic optimization of a UK advanced biofuel supply chain. Biomass and Bioenergy, 41, pp. 57-72, 2012.

[9] Awudu, I. \& Zhang, J., Stochastic production planning for a biofuel supply chain under demand and price uncertainties. Applied Energy, 103, pp. 189196, 2013.

[10] Bernardi, A., Giarola, S. \& Bezzo, F., Optimizing the economics and the carbon and water footprints of bioethanol supply chains. Biofuels Bioproducts and Biorefining, 6 (6), pp. 656-672, 2012.

[11] Giarola, S., Shah, N., Bezzo, F., A comprehensive approach to the design of ethanol supply chains including carbon trading effects. Bioresource Technology, 107, pp. 175-185, 2012.

[12] Domínguez-Faus, R., Powers, S.E., Burken, J.G. \& Alvarez, P.J., The water footprint of biofuels: A drink or drive issue? Environmental Science and Technology, 43, pp. 3005-3010, 2009.

[13] Hoekstra, A. Y., Chapagain, A. K., Aldaya, M.M. \& Mekonnen, M.M., The water foot-print assessment manual. Setting the global standard. Earthscan and the Water Footprint Network, London, U.K, 2011. 
[14] An, H., Wilhelm, W.E. \& Searcy, S. W., Biofuel and petroleum-based fuel supply chain research: A literature review. Biomass and Bioenergy, 35, pp. 3763-3774, 2011.

[15] Zhang, J., Osmani, A., Awudu, I. \& Gonela, V., An integrated optimization model for switchgrass-based bioethanol supply chain. Applied Energy, 102, pp. 1205-1217, 2013.

[16] Barisa, A., Romagnoli, F., Blumberga, A. \& Blumberga, D., Future biodiesel policy designs and consumption patterns in Latvia: a system dynamics model. Journal of Cleaner Production, 88, pp. 71-82, 2014.

[17] Månsson, A., Sanches-Pereira, A. \& Hermann, S., Biofuels for road transport: Analysing evolving supply chains in Sweden from an energy security perspective. Applied Energy, 123, pp. 349-357, 2014.

[18] Avinash, A., Subramaniam, D., Murugesan, A., Bio-diesel -A global scenario. Renewable and Sustainable Energy Reviews, 29, pp. 517-527, 2014.

[19] Hall, D.O. \& Scrase, J.I., Will biomass be the environmentally friendly fuel of the future? Biomass and Bioenergy, 15 (4-5), pp. 357-367, 1998.

[20] Love, B.J. \& Nejadhashemi, P., Water quality impact assessment of largescale biofuel crops expansion in agricultural regions of Michigan. Biomass and Bioenergy, 35, pp. 2200-2216, 2011.

[21] Ruini, L., Marino, M., Pignatelli, S., Laio, F. \& Ridolfi, L., Water footprint of a large-sized food company: The case of Barilla pasta production. Water Resources and Industry, 1-2, pp. 7-24, 2013.

[22] Aviso, K.B., Tan, R.R., Culaba, A.B. \& Cruz Jr., J.B., Fuzzy input-output model for optimizing eco-industrial supply chains under water footprint constraints. Journal of Cleaner Production, 19, pp. 187-196, 2011.

[23] Chapagain, A. K. \& Orr, S., An improved water footprint methodology linking global consumption to local water resources: A case of Spanish tomatoes. Journal of Environmental Management, 90, pp. 1219-1228, 2009.

[24] Gerbens-Leenes, W. \& Hoekstra, A.Y., The water footprint of sweeteners and bio-ethanol. Environment International, 40, pp. 202-211, 2012.

[25] Chooyok, P., The waterfootprint assessment of ethanol production from molasses in Kanchanaburi and Supanburi Province of Thailand. Proc. Of the International Conference on Environmental Science and Development eds. C.A. Pumijumnog, N., Ussawarujikulchai, A., Elsevier: Dubai, 5:283287, 2013.

[26] Su, M.H., Huang, C.H., Li, W.Y., Tso, C.T. \& Lur, H.S., Water footprint analysis of bioethanol energy crops in Taiwan. Journal of Cleaner Production, 88, pp. 132-138, 2015.

[27] Gerbens-Leenes, W., Hoekstra, A.Y. \& van der Meer, T.H., The water footprint of bioenergy. Proc. of the National Academy of Sciences, eds. C.A. D. Pimentel 106 (25), pp. 10219-10223, 2009.

[28] Deurer, M., Green, S.R., Clothier, B.E. \& Mowat, A., Can product water footprints indicate the hydrological impact of primary production? A case study of New Zealand kiwifruit. Journal of Hydrology, 408, pp. 246-256, 2011. 
[29] Galan-del-Castillo, E. \& Velazquez, E., From water to energy: The virtual water content and water footprint of biofuel consumption in Spain. Energy policy, 38, pp. 1345-1352, 2009.

[30] Aslani, A., Helo, P. \& Naaranoja, M., Role of renewable energy policies in energy dependency in Finland: System dynamics approach. Applied Energy, 113, pp. 758-765, 2014.

[31] Rendon-Sagardi, Miguel A., Sánchez-Ramírez, C., Cortes-Robles, G., AlorHernández, G. \& Cedillo-Campos, M.G., Dynamic analysis of feasibility in ethanol supply chain for biofuel production in Mexico. Applied Energy, 123, pp. 1-10, 2014.

[32] Forrester, J. W., Industrial dynamics: A major breakthrough for decision makers. Harvard Business Review, 36 (4), pp. 37-66, 1958.

[33] Rehan, R., Knight, M.A., Unger, A.J.A. \& Haas, C.T., Development of a system dynamics model for financially sustainable management of municipal watermain networks. Water Research, 47, pp. 7184-7205, 2013.

[34] Chen, Z. \& Wei, S., Application of system dynamics to water security research. Water Resources Management, 28, pp. 287-300, 2014.

[35] Jin, W., Xu, L. \& Yang, Z., Modeling a policy making framework for urban sustainability: Incorporating system dynamics into the ecological footprint. Ecological Economics, 68, pp. 2938-2949, 2009.

[36] Rehan, R., Knight, M.A., Unger, A.J.A. \& Haas, C.T., Financially sustainable management strategies for urban wastewater collection infrastructure -development of a system dynamics model. Tunneling and Underground Space Technology, 39, pp. 116-129, 2013.

[37] El-Gafy, I.K., System dynamic model for crop production, water footprint, and virtual water nexus. Water Resources Management, 28, pp. 4467-4490, 2014.

[38] Babel, M.S., Shrestha, B. \& Perret, S.R., Hydrological impact of biofuel production: A case study of the Khlong Phlo watershed in Thailand. Agricultural Water Management, 101, pp. 8-26, 2011. 